\title{
AÇÃO ANTIMICROBIANA DO Zingiber officinalle FRENTE À MICROBIOTA BUCAL
}

\author{
Antimicrobial activity from Zingiber officinalle \\ on oral cavity pathogens
}

\author{
Ana Maria Trindade Grégio ${ }^{1}$ \\ Edilene Sayuri Miyamoto Fortes ${ }^{2}$ \\ Edvaldo A. Ribeiro Rosa ${ }^{3}$ \\ Rossana Baggio Simeoni ${ }^{4}$ \\ Rosemeire Takaki Rosa ${ }^{5}$
}

\section{Resumo}

A fitoterapia tem sido alvo de investigações científicas, especialmente em países do oriente. No Brasil, também ocorre um especial interesse da comunidade científica quanto ao uso, efeito e propriedades farmacológicas das plantas medicinais, tendo o seu uso direcionado ao tratamento de várias doenças. A microbiota bucal é um dos locais em que há uma maior variedade de microrganismos que podem, por um desequilíbrio, tornar-se patogênicos. Baseado nisso, um estudo do extrato da Zingiber officinalle foi realizado para avaliar o seu potencial antimicrobiano, com microrganismos comumente encontrados na cavidade bucal, no qual foi obtida a concentração mínima inibitória do extrato de gengibre frente a alguns tipos de patógenos presentes na microbiota bucal do ser humano. Foi utilizado o método microbiológico no qual os extratos glicólico e hidroalcoólico do gengibre sofreram diluições seriadas no meio de cultura (BHI) para uma posterior inoculação dos microrganismos, Streptococcus mutans, Staphylococcus aureus, Escherichia coli e Candida albicans. Obteve-se a concentração mínima inibitória dos extratos de gengibre, tanto na sua forma glicólica quanto hidroalcoólica. A dose mínima necessária para inibir o crescimento dos vários microrganismos testados foi de $5 \mathrm{mg} / \mathrm{ml}$ dos dois extratos estudados. O extrato da Zingiber officinalle apresentou atividade antibacteriana e antifúngica relevante para a Odontologia, podendo contribuir para 0 tratamento de doenças causadas por esses microrganismos presentes na cavidade bucal.

Palavras-chave: Zingiber officinalle; Antimicrobiano; Gengibre.

\footnotetext{
Prof. a titular de Farmacologia - PUCPR; ana.gregio@pucpr.br.

Odontóloga-PUCPR, edimftes@gmail.com.

Prof. Adjunto de Microbiologia-PUCPR; edvaldo.rosa@pucpr.br.

Farmacêutica-Bioquímica-PUCPR.

5 M.Sc. Microbiologista-UNICAMP.
} 


\section{Abstract}

The fitoterapia has been investigated im many East countries. In Brazil, there is an special interest about effects, indications and pharmacology properties of natural medicine, that having its use directed to the treatment of some illnesses.

The oral flora is one of the places where it has a bigger variety of microrganismos that can, for a unstability, to become pathogenic. Based in this, a study of the extract of the Zingiber officinalle was carried through to evaluate its potential antimicrobials, with microrganisms commonly found in the oral cavity, in which the minimum inibitory concentration (MIC) of the ginger extract was gotten from some types of pathogens in the oral flor of the human. The microbiological method in which were used the extracts glicolic and hidroalcoolic from the ginger that they had suffered to dilutions in the way of culture (BHI) for a posterior inoculation them microrganisms, Streptococcus mutans, Staphylococcusaureus, Escherichia coli and Candida albicans. It was gotten a MIC of ginger extracts, as much in its how much hidroalcoolic and glicolic form. The MIC necessary to inhibit the growth of the some tested microrganisms was of $5 \mathrm{mg} / \mathrm{ml}$ of two studied extracts. The extract of the Zingiber officinalle showed excellent antibacterial and antifungical potential for the Odontologia, being able to contribute for the treatment of illnesses caused for these microrganisms in the oral cavity.

Keywords: Zingiber officinalle; Antimicrobial; Ginger.

\section{Introdução}

A fitoterapia tem sido amplamente utilizada pela população desde a antiguidade, porém, nos últimos anos, pesquisas vêem crescendo progressivamente. $\mathrm{O}$ uso de plantas medicinais é uma prática de quase todas as culturas, e no Brasil não é diferente, principalmente pela flora ser vasta e generosa, contribuindo muito para a terapêutica. Entre as diversas plantas existentes e utilizadas como terapia alternativa está o gengibre, cujo nome científico é Zingiber officinalle. Popularmente, o gengibre vem sendo empregado por meio de soluções e sprays, na cavidade oral, devido a sua ação cicatrizante, antiinflamatória e antimicrobiana. O gengibre é indicado, também, no tratamento de dores de cabeça, náusea e outras desordens estomacais, de resfriados e algumas outras infecções virais como a hepatite $C$, de osteoartrite, além de apresentar efeitos anticancerígenos. $\mathrm{O}$ gengibre é uma planta que cresce, preferencialmente, em clima úmido, a uma temperatura amena; fitoquimicamente, a planta apresenta de 1-3\% de óleo essencial (sesquiterpenos), 2,5 - 5\% de princípios picantes (gingerol e shogaol) e $60 \%$ de amido. Os gingeróis, principalmente o [6]-gingerol são identificados como os maiores constituintes dos rizomas de gengibre frescos e têm sido atribuídos a eles vários efeitos farmacológicos: analgésico, antipirético, atividade anti-hepatotóxica, antinauseante e antiinflamatória.

Basicamente os gingeróis e shogaóis são os responsáveis pela maior parte das atividades terapêuticas do gengibre. O shogaol, que é um produto da quebra de gingerol produzido durante a secagem, é duas vezes mais pungente que 0 gingerol (1). Investigando os efeitos dos componentes oleorresinosos do gengibre, Tjendraputra e col. (2) compararam a atividade dos gingeróis e shogaóis na inibição da enzima ciclooxigenase do tipo 2. Tal enzima é um produto da ativação do ácido araquidônico e é conhecida como a ciclooxigenase induzível no processo inflamatório. Tanto os gingeróis como os shogaóis foram capazes de inibir a ciclooxigenase- 2 em modelos experimentais in vitro.

A sua ação antiinflamatória e cicatrizante, e o seu uso sobre a mucosa oral, encontram-se pouco esclarecidos na literatura científica. O processo inflamatório é mediado por uma série de mediadores que promovem e facilitam a transmissão dolorosa, hiperalgesia e as alterações clássicas periféricas como dor, calor, rubor, aumento da permeabilidade vascular, atração de células fagocitárias, neutrófilos, linfócitos e polimorfonucleares. O suco fresco de gengibre foi descrito como alívio efetivo contra dor, bolhas e inflamação provocada por queimaduras, sem causar irritação (3). Um estudo realizado por Pedroso-Mariani (4) verificou a capacidade antiinflamatória do extrato dos rizomas do gengibre sobre o edema de pele de ratos e observou que o composto oleorresinoso, quando aplicado topicamente, provocava uma diminuição do edema, porém resultados similares não fo- 
ram encontrados quando o gengibre foi utilizado na sua forma de extrato aquoso, muito provavelmente em função de que os compostos oleorresinosos detenham as suas propriedades terapêuticas antiinflamatórias. Da mesma forma, Medeiros (5) observou que o extrato cetônico do gengibre possuía atividade antiedematogênica e analgésica no modelo de analgesia e inflamação em ratos Wistar, concluindo ainda que o gengibre teria possivelmente capacidade para reduzir os produtos do metabolismo do acido araquidônico.

Além de todas as propriedades apresentadas pelo gengibre, a sua atividade antimicrobiana está sendo bastante estudada. Pesquisas mostram que óleos e extratos de Zingiber officinalle apresentam ação inibitória em bactérias gram positivas e gram negativas, porém ainda há poucos estudos que relacionam o gengibre aos microrganismos prevalentes na cavidade bucal, visto que esta apresenta uma flora bastante variada e que pode desencadear inúmeras patogenias.

\section{Método}

\section{1- Obtenção dos ex tratos}

\section{Ex tração oleorresina - Ex tra to oleorresinoso (EO)}

A extração dos compostos oleorresinosos do gengibre foi realizada por meio da técnica do "arraste a vapor" com auxílio de um clevenger. Os rizomas in natura foram colhidos, lavados e encaminhados a uma estufa de ar para que fossem secos, a uma temperatura de $90^{\circ} \mathrm{C}$ a $106^{\circ} \mathrm{C}$.

\section{Ex tra to eta nólico - Ex tra to eta nólico do gengibre (EEG)}

Uma amostra do gengibre foi pesada e transferida a um extrator tipo Soxhlet. Após a extração, a amostra foi macerada durante seis horas, em temperatura ambiente para, posteriormente, ser filtrada e ser levada ao rotaevaporador a $40^{\circ} \mathrm{C}$. A fase aquosa foi deixada em um dessecador com sílica gel por 24 horas e depois liofilizada.

\section{Ex tra to glicólico e hidroa lcoólico de gengibre}

Estes foram feitos com uma extração a frio, cuja principal diferença foi o solvente aplicado - propilenoglicol (glicólico) e água e álcool (hidroalcoólico).

Raízes secas de Zingiber officinalle foram cortadas em fragmentos pequenos e moídas. Cinco volumes de solvente foram adicionados ao gengibre moído e a suspensão foi filtrada; o resíduo obtido sofreu o mesmo tratamento por mais duas vezes. Os filtrados resultantes de cada etapa de filtração foram reunidos e concentrados até a secura, sob pressão, em temperatura inferior a $30^{\circ} \mathrm{C}$.

\section{2 - Técnica de inibição de microrganismos}

\section{1..$^{0}$ Teste - Difusão dos cilindros - oleorresina}

Essa técnica consistiu na difusão de $100 \mu \mathrm{L}$ da oleorresina, em diferentes concentrações, por meio de cilindros de aço inoxidável que foram dispostos, perpendicularmente, sobre a superfície dos meios em que os microrganismos haviam sido inoculados. Os microrganismos utilizados foram: Staphylococcus aureus, Streptococcus mutans, Escherichia coli e Candida albicans. As placas foram incubadas a $37^{\circ} \mathrm{C}$ por 48 horas, com exceção da placa do Streptococcus mutans em que foi utilizado o método de microaerofilia (método da vela) num período de 24 horas.

\section{2..$^{\circ}$ Teste - Difusão dos cilindros - gel de gengibre}

Num segundo momento, foi desenvolvido um gel com o óleo de gengibre, utilizando o carbopol, que promove a consistência de gel. Os microrganismos testados foram o Staphylococcus aureus, Streptococcus mutans e Candida albicans. Os testes foram feitos em duplicata, sendo utilizadas um total de seis placas de Petri. Em cada placa foram feitas quatro perfurações por um cilindro e colocado o gel para que ocorresse a sua difusão. Assim, as placas foram levadas a uma estufa a $37^{\circ} \mathrm{C}$ por 24 horas, com exceção da placa do 
Streptococcus mutans que foi incubada pelo méto do da microaerofilia por 24 horas.

\section{3ํㅜㄹ - Exte tratos fluídos de gengibre}

Esse teste foi realizado utilizando os extratos glicólico e hidroalcoólico extraídos a frio. Pelas diluições seriadas, esses extratos foram analisados quanto a sua atividade antimicrobiológica. Os microrganismos testados foram Staphylococcus aureus, Streptococcus mutans, Escherichia coli e Candida albicans. Este experimento consistiu em 7 diluições seriadas de $238 \mu \mathrm{L}$ de cada extrato, distribuídos no meio de cultura BHI presentes nos tubos de ensaio (foram utilizados 112 tubos e em cada tubo foi colocado $1 \mathrm{ml}$ do extrato, exceto nos tubos $\mathrm{n} \mathbf{0} 1$, no qual havia $2 \mathrm{ml}$ ). O trabalho foi realizado em duplicata e para cada microrganismo foram utilizados 28 tubos de ensaio, sendo que 14 correspondiam ao extrato glicólico e os outros 14 ao extrato hidroalcoólico do gengibre. Posteriormente, os microrganismos foram inoculados em cada um dos tubos de ensaio e estes foram levados a uma estufa com uma temperatura de

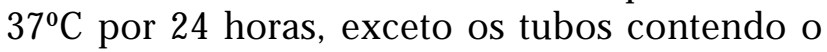
Streptococcus mutans que foram incubados pelo método de microaerofilia.

\section{Resultados}

Após a incubação dos microrganismos, procedeu-se à determinação da susceptibilidade deles por meio da medição dos halos de inibição de crescimento ao redor dos cilindros (no 1.o experimento realizado) e ao redor das perfurações realizadas (no 2.․o experimento). Os microrganismos avaliados não apresentaram susceptibilidade ao óleo de Zingiber officinalle nem ao seu extrato etanólico.

A concentração mínima inibitória do gengibre foi obtida a partir dos extratos glicólico e hidroalcoólico, sendo esta de 5mg/ $\mathrm{ml}$ de dose mínima necessária para inibir 0 crescimento dos microrganismos testados, Staphylococcus aureus, Streptococcus mutans, Escherichia coli e Candida albicans. Houve êxito nos ensaios microbiológicos, por meio do método de extração do gengibre a frio ( $3^{\circ}$ teste realizado).

\section{Discussões e Conclusões}

Levantamentos de ordem farmacológica têm despertado grande interesse por produtos de origem natural, em função de sua vasta aplicabilidade clínica nos diferentes campos da prática médico-odontológica. Estudos e ensaios físico-químicos e microbiológicos devem ser levados a termo, cada vez que se detecta uma fonte terapêutica de um fitofármaco. O extrato etanólico do gengibre (EEG) e o óleo essencial não apresentaram atividade antimicrobiana efetiva, segundo as condições experimentais empregadas, uma vez que os componentes do gengibre são termolábeis, podendo ter perdido os seus efeitos antimicrobianos, no momento da sua obtenção. De acordo com Chen, Chang e Chang (6), os princípios ativos antimicrobianos de diversas plantas empregadas como temperos culinários são termolábeis. No caso específico do gengibre, os autores relataram que, após o aquecimento, este reduziu a sua atividade antimicrobiana. Ao contrário dos resultados obtidos por Farias e col. (3), o óleo essencial do gengibre não promoveu efeito terapêutico e antimicrobiano desejado, porém verificaram mais eficiência do óleo essencial em relação ao extrato hidroalcoólico no processo de reparo de lesões. Foi relatado por Mascolo e col. (7) a atividade antiproliferativa do EEG contra diversas bactérias. Nossos resultados encontram-se em desacordo, não apresentando halos de inibição detectáveis. Cabe ressaltar que os autores acima obtiveram o EEG por via fria, ao passo que em nosso estudo a extração do óleo essencial de gengibre foi realizada por arraste a vapor e o EEG foi obtido por extração em aparelho de Soxhlet. Em ambos os procedimentos, as moléculas bioativas foram submetidas a altas temperaturas. Quando o gengibre foi testado na forma de extrato hidroalcoólico e glicólico (extração a frio), os resultados encontrados foram similares àqueles de Alzoreky e Nakahara (8), quanto ao tipo de microrganismo analisado. Porém houve divergências na concentração mínima inibitória (MIC) obtida. Nossos experimentos revelaram que $5 \mathrm{mg} / \mathrm{ml}$ do extrato foi suficiente, em contrapartida aos destes pesquisadores que demonstraram uma MIC de $660 \mathrm{mg} / \mathrm{ml}$. A ação antimicrobiana do gengibre foi estudada por Akoachere e col. (9) para combater os agentes patogênicos do trato respiratório. $O$ gengibre na sua forma de extrato etanólico foi eficaz na MIC 
Ação antimicrobiana do Zingiber officinalle frente à microbiota bucal

de 0,0003 $\mu \mathrm{g} / \mathrm{ml}$ a $0,7 \mu \mathrm{g} / \mathrm{ml}$. Essa discrepância de doses quando comparada ao nosso trabalho, pode ser explicada pelas variações de sazonalidade, de geografia e biodiversidade que interferem nas propriedades farmacológicas do gengibre $(10,11,12$, $13,14)$. Da mesma forma, Lopez e col. (15) analisaram a eficácia de seis óleos essenciais, incluindo a Zingiber officinalle em alguns microrganismos, entre eles Staphylococcus aureus, Escherichia coli e Cândida albicans. Foi mostrada uma atividade antimicrobiana de todos os óleos essenciais, porém o do gengibre foi um dos que apresentou um resultado pouco favorável. Provavelmente, este fato se deva à forma de extração dos princípios ativos oleorresinosos e à termolabilidade destes.

Um estudo realizado por Konning, Agyare, Ennison (16), analisou a atividade antimicrobiana do extrato metanólico de algumas plantas medicinais oriundas do Ghana, entre elas o Zingiber officinalle. Esta forma de extração foi eficaz contra bactérias gram positivas e gram negativas, além de terem apresentado uma atividade antifúngica relevante.

Foi verificada por Nguefack, Budde, Jakobsen (17) a atividade antimicrobiana do óleo essencial do gengibre em diferentes microrganismos, incluindo o Staphylococcus aureus, o que vem a sedimentar os nossos achados. Todos os resultados vêm a corroborar o potencial antimicrobiano do Zingiber officinalle, sendo este de grande relevância, pois auxiliará no tratamento de enfermidades provocadas por esses patógenos.

\section{Referências}

1. Surh YJ, Park KK, Chun KS, Lee LJ, Lee SS. Anti-tumor promoting potential of selected spice ingredients with antioxidative and antiinflamatory activities: a short review. Food Chem. Toxicology, Seoul 2002; 40(8):1091-1097.

2. Tjendraputra E, Tran VH, Liu-Brennan D, Roufogalis BD, Duke CC. Effect of ginger constituints and synthetic analogues on ciclooxygenase-2 enzyme in intact cells. Bioorg Chem, Australia 2001; 29(3):156-163.

3. Farias MM, Gomes MCB, Lima AAS, Azevedo LR, Pereira ACP, Grégio AMT. Efeito das frações do Zingiber officinalle sobre o processo de reparo de lesões ulceradas na mucosa bucal de ratos. Pesquisa Odontológica Brasileira, Brasil 2005; 19:75.

4. Pedroso-Mariani S. Effects of Zingiber officinale in the paw oedema the rats induced by caragenin. X FESBE- Federação das Sociedades de Biologia Experimental 1995; 10:241.

5. Medeiros MV. Effects therapeutic of Zingiber officinale in experimental models of analgesic and inflammation. X FESBE- Federação das Sociedades de Biologia Experimental 1995; 10:243.

6. Chen HC, Chang MD, Chang TJ. Antibacterial properties of some spice plants before and after heat treatment. Zhonghua Min Guo Wei Sheng Wu Ji Mian Yi Xue Za Zhi, China 1985; 18(3):190-195.

7. Mascolo N, Jain R, Jain SC, Capasso F. Ethnopharmacologic investigation of ginger (Zingiber officinales). J Ethnopharmacol 1989; 27:129-140.

8. Alzoreky NS, Nakahara K. Antibacterial activity of extracts from some edible plants commonly consumed in Asia. Journal Food Microbiology, Yemen 2003; 80(3):223-230.

9. Akoachere JF, Ndip RN, Chenwi EB, Ndip LM, Njock TE, Anong DN. Antibacterial effect of Zingiber officinale and Garcinia kola on respiratory tract pathogens. East Afr Med Journal, Cameroon 2002; 79(11):588-592.

10. Doussot F, de Jeso B, Quideau S, Pardon P. Extractives content in cooperage oak wood during natural seasoning and toasting; influence of tree species, geographic location, and singletree effects. Journal Agric Food Chem, França 2002; 50(2):5955-5961.

11. Talley SM, Coley PD, KursarTA. Antifungal leafsurface metabolites correlate with fungal abundance in sagebrush populations. Journal Chem Ecol 2002; 28(11):2141-2168.

12. Chung HY, Ma WC, Ang PO JR, Kim JS, Chen F. Seasonal variations of bromophenols in brown algae (Padina arborescens, Sargassum siliquastrum, and Lobophora variegata) collected in Hong Kong. J Agric Food Chem, Hong Kong 2003; 51(9):2619-2624. 
13. Taveira SM, Andrade EH, Lima WN, Maia JG. Seasonal variation in the essential oil of pilocarpus microphyllus Stapf. An Acad Bras Cienc 2003; 75(1):27-31.

14. Vetter W, Weichbrodt M, Stoll E, Indication of geographic variations of organochlorine concentrations in the blubber of Antartic Weddell seals (Leptonychotes weddelli). Environ Sci Technol 2003; 37(5):840-844.

15. Lopez P, Sanchez C, Batlle R, Nerin C. Solidand vapor-phase antimicrobial activities of six essential oils: susceptibility of selected foodborne bacterial and fungal strains. J Agric Food Chem, Zaragoza 2005; 53(17):6939-6946.
16. Konning GH, Agyare C, Enisson B. Antimicrobial activity of some medicinal plants from Ghana. Fitoterapia, Kumasi 2004; 75(1):65-67.

17. Nguefack, J, Budde BB, Jakobsen M, Five essential oils from aromatic plants of Cameroon: their antibacterial activity and ability to permeabilize the cytoplasmic membrane of Listeria innocua examined by flow cytometry. Lett. Appl. Microbiology, Yaounde 2004; 39(5):395-400.

Recebido em / Received: November 9, 2005. Aceito em / Accepted: January 27, 2006. 